Para enlazar con este artículo / To link to this article:

http://dx.doi.org/10.14198/fem.2018.32.01

Para citar este artículo / To cite this article:

Barberá Pastor, Carlos y Pardo Marín, Rosa. «El lavadero donde la mujer lava. Un espacio contradictorio y difuso en las políticas urbanas». En Feminismo/s, 32 (diciembre 2018): 23-47. Dosier monográfico: MAS-MES: Mujeres, Arquitectura y Sostenibilidad - Medioambiental, Económica y Social, coord. María-Elia Gutiérrez-Mozo, DOI: 10.14198/fem.2018.32.01

\title{
EL LAVADERO DONDE LA MUJER LAVA. UN ESPACIO CONTRADICTORIO Y DIFUSO EN LAS POLÍTICAS URBANAS
}

\section{WASHHOUSES WHERE WOMEN WASH. A CONTRADICTORY AND DIFFUSE SPACE IN URBAN POLICIES}

\author{
Carlos BARBERÁ PASTOR \\ Universidad de Alicante \\ carlos.barbera@ua.es \\ orcid.org/0000-0003-3401-3670 \\ Rosa PARDO MARÍN \\ Universitat Politècnica de València \\ pardo.rosa@gmail.com \\ orcid.org/0000-0002-5292-3195
}

\section{Resumen}

La globalización, que se caracteriza por una fuerte interrelación y dependencia a nivel mundial, conlleva una creciente homogeneización de aspectos económicos, tecnológicos y culturales. Sin embargo, el territorio sigue siendo un hecho diferenciado en cada región debido a factores naturales propios, pero también a prácticas humanas que lo transforman adaptándolo a necesidades y circunstancias locales. Cada territorio genera experiencias de vida diversas cuya memoria se refleja en el paisaje, el espacio urbano o el patrimonio, imprimiendo un carácter y una identidad particular a cada lugar. Uno de los factores determinantes en la configuración del paisaje es el agua y es un hecho universal la relación de las mujeres con tareas relacionadas con el agua. En esta curiosa interrelación entre globalización y lógicas locales el estudio de los lavaderos nos da la oportunidad de caracterizar un paisaje concreto de manera integral e indagar, al mismo tiempo, otras cuestiones relacionadas con las condiciones de trabajo de las mujeres y su memoria. La Nueva Agenda Urbana podría proveer un urbanismo más sostenible teniendo en cuenta todo ello. 


\begin{abstract}
The globalization process, characterised by major worldwide interrelation and dependency, is entailing increasingly uniform economic, technological and cultural aspects. Territory nevertheless continues to be a different reality in each part of the planet due to natural factors (geomorphology, soil or climate), but also to human practices transforming this to adapt to local needs and circumstances. Each area thus generates diverse life experiences whose memory is reflected in the landscape, in urban areas or heritage, giving each place its specific character and identity. One of the determining factors in forming the landscape is water and it seems a universal fact that women are assigned many tasks involving water. In this curious interrelation between global and local spheres the study of washhouses is used for comprehensively characterising a particular landscape but with a specific use of space than concerns women's work conditions and memory. The New Urban Agenda could provide a better sustainable urbanization linked with that.
\end{abstract}

\title{
1. PREÁMBULO
}

El ofrecimiento de la revista Feminismo/s para desarrollar un número sobre los Objetivos de Desarrollo Sostenible en relación a la Arquitectura, el Urbanismo y el Género, es uno de los precedentes de este artículo. El estudio iniciado por su autora, a partir de un trabajo de campo desarrollado sobre los lavaderos de las regiones mediterráneas, concibe unos materiales que ponen en relación espacios, tiempos, e ideales, de lo más diverso y heterogéneo. El artículo trata de poner en valor un lavadero en sí desde un marco que se ubica en universos dispares: entre acuerdos mundiales y los acontecimientos de recónditos lugares rurales. Plantea crear vínculos entre condiciones implícitas para el uso, con todo lo que ello conlleva, y los planteamientos de la Nueva Agenda Urbana desde un carácter internacional. Entre las particularidades que marcan sus usuarias, según una tradición o una cultura, y la impersonalidad de un documento que define cómo ha de ser usado, el artículo entrelaza concreción y generalidad. La disimilitud nos ha llevado a plantear ejemplos diversos traídos del cine, de los viajes, o del mismo trabajo de campo, así como escritos o interpretaciones que plantean separar aún más las coincidencias. Es, en una segunda parte, donde tratamos de mostrar una interpretación que desgrana el carácter del espacio femenino de un lavadero en relación a la mujer y su explotación laboral como un planteamiento que busca distancias para hacer entender la complejidad de tan múltiples variables.

Feminismo/s 32, diciembre 2018, pp. 23-47 

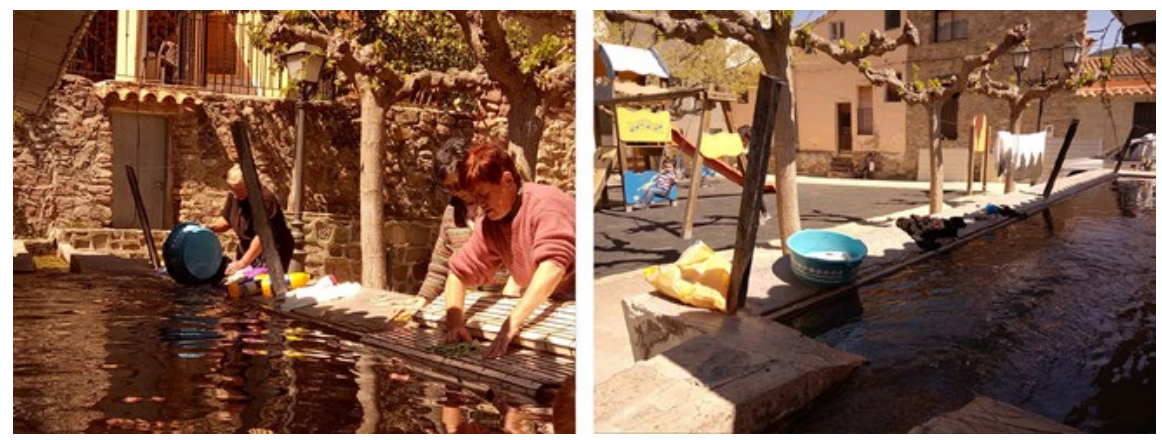

Figura 1. Mujeres lavando en Montán en abril de 2017. (Fotografías de Daniel Gómez Morales).

\section{2}

Años atrás, los lavaderos tuvieron un papel significativo como lugar de encuentro femenino y espacio de socialización, donde lo vivido se enmarcaba en códigos simbólicos propios que hoy se diluyen en la memoria callada de sus protagonistas $^{1}$. La realidad es que, con el transcurso del tiempo y desde la llegada del agua corriente a los hogares, los lavaderos han ido cayendo en desuso y desapareciendo en muchas poblaciones -sin apenas oposición o resistencia por parte de la ciudadanía-, aunque lo cierto es que, en la Península Ibérica, una pequeña proporción de mujeres todavía los utiliza² (figura 1). Quizás deberíamos decir personas, y no mujeres, para evitar impregnar de estereotipos nuestro artículo, pero sin embargo son ellas, mujeres del mundo rural con un fuerte arraigo en sus tradiciones, quienes dan vida a estos espacios realizando un uso prácticamente exclusivo de su género.

Ante esta realidad que presenta distintas velocidades -con un grado de tecnificación e industrialización mucho mayor en las zonas urbanas y

1. Se trata de una memoria parcial cuyo recuerdo lo poseen únicamente a las mujeres que usan o han usado los lavaderos, una memoria que no ha sido escrita por sus protagonistas y que reflejan con fidelidad pocas investigaciones. Analizando algunos documentos podríamos interpretar incluso que esta memoria ha sido silenciada.

2. En muchas otras poblaciones de la Comunitat Valenciana también se mantiene este uso, y podemos citar algunas que hemos visitado como Cirat, Castillo de Villamalefa, Benlloch, Vallat, Benifairó de la Valldigan, Vilamarxant, La Monzona (Puebla de Arenoso), Torres Torres, Cinctorres, Carrícola o Tuéjar.

Feminismo/s 32, diciembre 2018, pp. 23-47 
la persistencia de una vida más relacionada con los recursos naturales en ámbitos rurales- nos preguntamos qué expectativas o soluciones plantean las políticas de desarrollo mundiales, específicamente, para los espacios destinados al lavado de prendas. Nos referimos a las relaciones funcionales de éstos con la ciudad -como podrían ser los recorridos de acceso- $u$ otras cuestiones simbólicas y prácticas en torno a los lavaderos que pudieran incidir en patrones de uso y disfrute más igualitarios por parte de toda la ciudadanía.

La Nueva Agenda Urbana, aprobada en la Conferencia de las Naciones Unidas sobre la Vivienda y el Desarrollo Urbano Sostenible (Hábitat III) celebrada en Quito, Ecuador, en 2016, y refrendada por la Asamblea General de las Naciones Unidas en diciembre del mismo año, plantea un ideal común: lograr «un futuro mejor y más sostenible, en el que todas las personas gocen de igualdad de derechos y de acceso a los beneficios y oportunidades que las ciudades pueden ofrecer, y en el que la comunidad internacional reconsidere los sistemas urbanos y la forma física de nuestros espacios como un medio para lograrlo» (ONU, Hábitat III, NAU iv). Esta Nueva Agenda Urbana, que debe ser adaptada y aplicada en los diferentes países teniendo en cuenta sus distintas realidades, capacidades, legislaciones y niveles de desarrollo nacionales, entronca con las directrices y criterios formulados en la Agenda 2030 para el Desarrollo Sostenible, el Acuerdo de París y otros acuerdos mundiales para el desarrollo. La intención común en todos ellos es contar con un futuro sostenible, tanto en los países en desarrollo como en los países desarrollados. Pero, ¿qué sucede al formular ese futuro en los espacios de lavado de prendas?

El caso concreto del lavado de prendas, como otras tareas relacionadas con el agua, representa una cuestión eminentemente femenina en todas las culturas del mundo. Probablemente, esto se deba a la íntima relación entre la esfera doméstica, o esfera reproductiva dicho en otros términos, y actividades como las de acarrear agua -para el consumo humano, la alimentación o la higiene- o las del lavado de prendas y utensilios de cocina. En el entorno mediterráneo, enmarcado en un contexto europeo, esta tarea podría considerarse minoritaria en la actualidad, aunque ello no justificaría su desatención pues, precisamente, el esfuerzo de estas políticas se centra en las necesidades de las personas más vulnerables o pobres como representan estas mujeres en su frágil condición de minoría. Por otra parte, en otras regiones del mundo menos desarrolladas, la recogida de agua o el lavado de prendas siguen siendo

Feminismo/s 32, diciembre 2018, pp. 23-47 
actividades cotidianas en la vida de muchas niñas y mujeres y, en ocasiones, algunos niños. Los hombres, salvo contadas excepciones, no participan en estas actividades o no son capaces de reconocerse en ellas, dado el profundo estigma con que la sociedad marca los estereotipos de género y cuya trasgresión se aprecia de un modo vergonzante.

Una visita a la ciudad de Chefchaouen, realizada en marzo de 2016, puede servir para ilustrar este último supuesto. Nos encontramos recorriendo el itinerario pedagógico paisajístico del Adarve del Agua, que constituye el límite físico de la ciudad por el este junto al río Oued Fourrad y por el que, además de fuentes y molinos, observamos varios lavaderos. Algunos de ellos se encuentran muy animados gracias a la actividad y al colorido con que las mujeres chaníes impregnan el lugar, mientras que algún otro, en un lugar algo más reservado descendiendo por el estrecho valle agrícola, está tranquilo y encontramos allí a un joven solo (figura 2). El muchacho, al advertir nuestro interés en esta construcción, inicia una conversación explicándonos que se
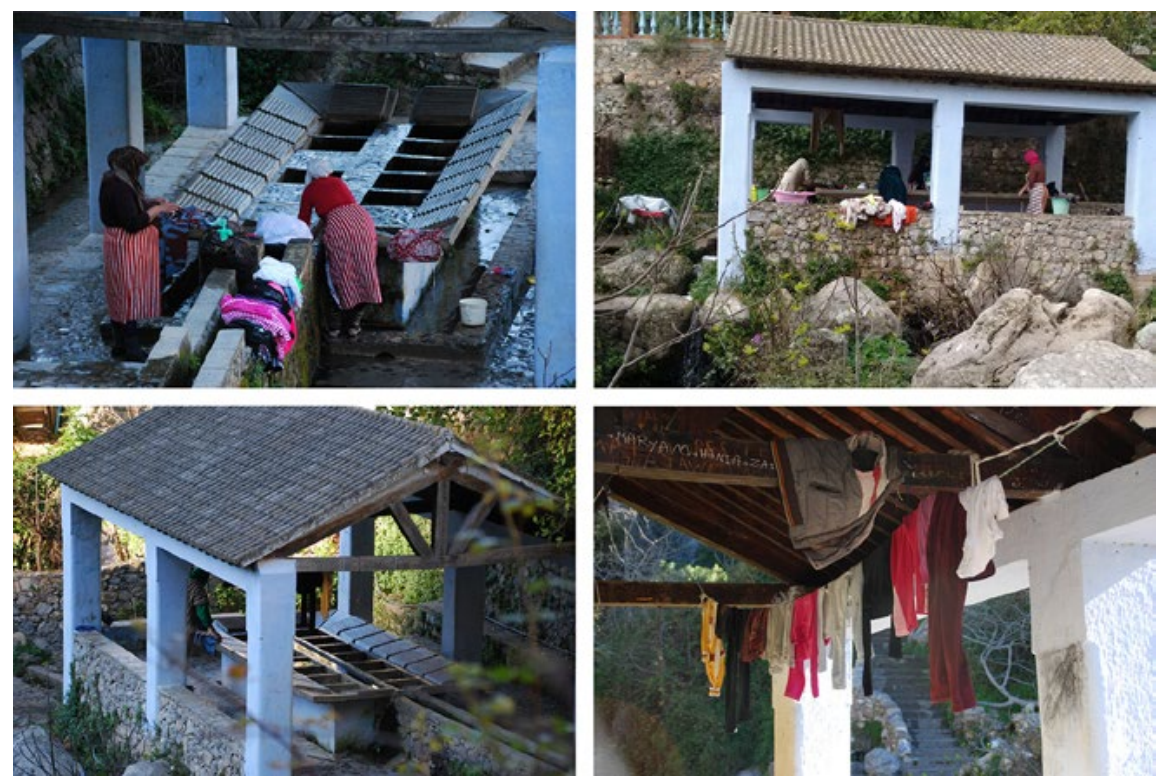

Figura 2. Lavaderos en el itinerario pedagógico paisajístico del Adarve del Agua de Chefchaouen (Marruecos), en 2016. (Fotografías de Daniel Gómez Morales y Rosa Pardo i Marín).

Feminismo/s 32, diciembre 2018, pp. 23-47 
trata de un lugar donde las mujeres lavan la ropa; le respondemos que las mujeres y él lo hacen, pero su respuesta es negativa y se excusa explicando que se trata sólo de unas pocas prendas. Independientemente de la cantidad de piezas que lavara, su respuesta sugiere que no se sentía en «su» lugar.

Huelga decir que, en general, los lavaderos suelen ser espacios y construcciones abiertas, sin ningún tipo de barrera física ni normas escritas que impidieran ni restringieran el libre acceso, pero en la práctica los hombres no participaban de esa realidad. Esto pone en evidencia que la segregación espacial de la ciudad está, sobretodo, en nuestra mente, alimentada y consolidada a partir de discursos y relatos en los que la arquitectura no está exenta de responsabilidad.

Existen referencias evidentes de la complicidad de la arquitectura en el ejercicio de la autoridad patriarcal, según comenta Mark Wigley en una cita al «tractat del segle qinze On the Art of Building in Ten Books d'Alberti» explicando con detalle cómo ordenar espacialmente la vivienda para vigilar adecuadamente las cuestiones de género: «Cal tancar la dona dins la profunditat d'una seqüencia d'espais, a la distanciamés gran posible del món exterior, mentre que l'home ha de ser exposat a aquest exterior. La casa s'entén literalment com un mecanisme per a la domesticació de la dona (de ment delicada i de cos patològic)» (Wigley 212). Aunque hoy nos parezcan escandalosas unas declaraciones así por parte de un arquitecto, podemos encontrar mensajes sexistas mucho más sutiles en la producción arquitectónica actual. Si nos fijamos en la representación gráfica de los concursos de arquitectura o urbanismo actuales, las imágenes $3 \mathrm{D}$, las secciones o las perspectivas se aderezan con siluetas e imágenes de personas en actitudes ociosas, que disfrutan del espacio proyectado, apelando a las conciencias de una manera emotiva. Este tipo de imagen es relativamente reciente, por lo que nos sorprende que, en el proyecto de 1.921 para el lavadero público de Godella, un pueblo muy próximo a Valencia, el arquitecto incorpore, en la sección -una solución ingeniosa que resuelve con inteligencia el desnivel desde la cota de captación del agua en la acequia de Moncada hasta la del lavadero, a una cota inferior- las figuras de dos mujeres lavando. Esta imagen bien podría servir para evidenciar el confort esperado de esta infraestructura hidráulica, atento a la ergonomía de las personas, aunque también nos recuerda a qué personas les corresponde utilizar esta construcción (figura 3).

Feminismo/s 32, diciembre 2018, pp. 23-47 


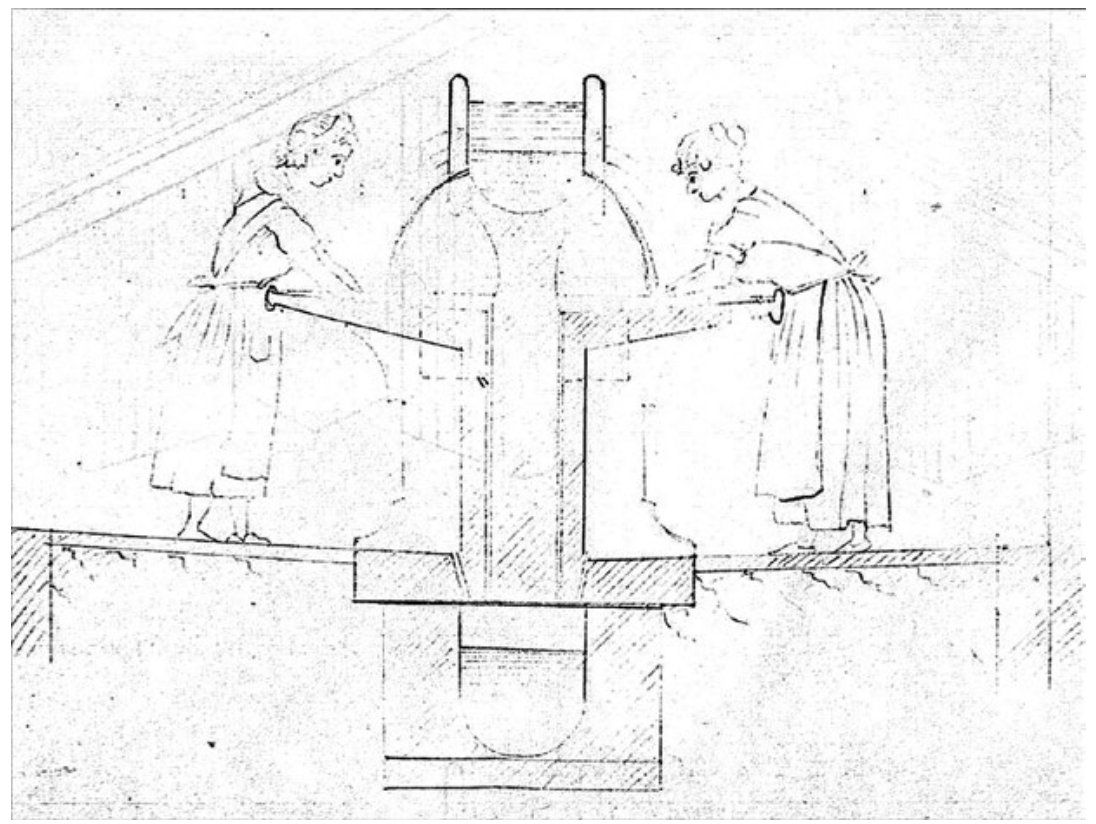

Figura 3: Sección del proyecto de Francisco Almenar para el lavadero público de Godella, ya desaparecido. La imagen se ha escaneado y tratado a partir de una fotocopia conservada en el archivo de los arquitectos Vicent García y Pepe Murcia. El plano original no se ha podido localizar en ninguno de los archivos consultados (CTAV, Archivo Municipal y archivo del Taller de Historia Local).

Si retomamos el tema de la Agenda 2030, no son gratuitas estas alusiones al agua ni al uso del lavadero por parte de la mujer. Resulta cuanto menos curioso que el ciclo integral del agua esté organizado y controlado por hombres normalmente, a pesar de representar una necesidad cotidiana para ellas. Además, la participación activa de las mujeres no se limita a actividades como transportar o lavar, sino que también desempeñan otras tareas relacionadas con la agricultura. En muchos lugares donde el agua es un bien escaso, existe una fuerte relación entre todas esas actividades, ya que las aguas resultantes tras los procesos de lavado se recuperan y se reutilizan para el riego de los cultivos.

Quizás se ha visibilizado poco el trabajo de las mujeres en el campo y, con idéntica dificultad para aceptar y reconocer la permeabilidad de los roles que hemos ejemplificado antes con la anécdota de Chefchaouen, las mujeres

Feminismo/s 32, diciembre 2018, pp. 23-47 
también reproducen esta perplejidad cuando nos hablan de sus «trabajos» o de las «ayudas» que procuran a otros. Así lo interpretamos, al menos, a partir de las entrevistas realizadas en nuestro trabajo de campo y que consideramos una de las fuentes de información relevantes de este artículo. En una de estas entrevistas Josefina nos habla del entorno de uno de los lavaderos de Tuéjar y su relación con el mismo ${ }^{3}$ :

No pasaban agricultores, porque no era un lugar de paso. Eran caminos estrechos, que si pasaban a hacer algo en las tierras tenían que llevar caballerías, que no cabía ni un tractor ni un coche ni nada. Yo me acercaba a lo mejor a ver lo que tenía mi hermano, a ver tomates y muchas cosas así (estaba como a 500 metros). Veíamos a los labradores que pasaban por la ronda arriba, con carros, con caballerías y decíamos «el novio de la Clemencia», y la Clemencia se ponía con unos colores así... El abuelo tenía un campo en la parte del lavadero de la rocha la Fuente, en el camino viejo de Chelva. Las mujeres participaban mucho en los campos, hasta en el monte que se ponía trigo y avena, íbamos a escardar, a sacar las hierbas. Cuando los hombres segaban, nosotras íbamos a recoger las espigas que dejaban en el suelo. Nosotras les hacíamos la comida y estábamos hasta las tantas de la noche que nos veníamos con el burro. Después yo en las huertas ¡madre si he participado! Íbamos a coger tomate, a por alfalfa, a recoger cebolla, a ayudarles a echar las patatas...

Pero a pesar de estas evidencias de trabajo compartido y de que el trabajo realizado por las mujeres resolvía necesidades básicas, históricamente se ha considerado que las tareas que ellas desempeñaban eran secundarias y se les ha relegado en la toma de decisiones. Incluso podrían haberse considerado como fuente de conflictos.

En Fuenterrobles, por ejemplo, además del lavadero que aún se conserva «existió otro aguas abajo, para otros usos, que dejó de utilizarse en la década de los años sesenta del siglo pasado y actualmente no se conserva nada. Este lavadero que empezó a tramitar su construcción en 1851, tuvo que normalizar una situación complicada, ya que se alegaba que las mujeres modificaban el curso del agua para lavar, con los consiguientes problemas para el regadío» (Moya Muñoz 55).

En la provincia de Valencia es fácil comprobar esta ausencia de representatividad femenina en la gestión del agua con otros ejemplos, como la

3. Esta entrevista se realizó en el año 2016 gracias a la colaboración de Consu Pérez Solaz.

Feminismo/s 32, diciembre 2018, pp. 23-47 
composición del Tribunal de las Aguas o la figura del síndico en la Real Acequia de Moncada, que corresponden exclusivamente a hombres.

El origen de estas interpretaciones que consideran secundarias algunas tareas, como hemos dicho, quizás podamos encontrarlo en la disociación que el mercado de trabajo otorga, mediante la remuneración a unos u otros tipos de trabajos desempeñados. La realidad percibida y la otra realidad que podríamos medir de manera objetiva a partir del tiempo y del esfuerzo aplicado, arrojan en este sentido datos dispares e irreconciliables. Vistas todas estas cuestiones previas, entendemos que el tema de los lavaderos estaría relacionado directamente con varios Objetivos de Desarrollo Sostenible (ODS) definidos en la Agenda 2030, en particular: con el objetivo 5, centrado en «lograr la igualdad de género y empoderar a todas las mujeres y las niñas»; el objetivo 6, cuya intención es «garantizar la disponibilidad y la gestión sostenible del agua y el saneamiento para todos»; y el objetivo 11, orientado a «lograr que las ciudades y los asentamientos humanos sean inclusivos, seguros, resilientes y sostenibles». En realidad, analizando estos espacios en un sentido amplio que comprendería tanto el lavado a orillas de ríos o acequias como el realizado en infraestructuras específicas como los lavaderos, lavanderías u otras soluciones o servicios equiparables, se debería reconocer que esta actividad tiene múltiples implicaciones y repercusiones sobre casi todos los objetivos planteados en la Agenda 2030 en su triple dimensión social, económica y ambiental, evidenciando la interdependencia entre todos ellos.

Ahora bien, no debemos pasar por alto que estos documentos fijan un horizonte muy amplio y genérico para cualquier tema y, a pesar de hacer hincapié en necesidades concretas relacionadas con el tema central que nos ocupa, carecen de capacidad ejecutiva directamente aplicable y requieren, por ello, concreción y definición a niveles regionales y locales.

Por poner algunos ejemplos: se reivindica el papel de las mujeres en la economía local y en la agricultura, se llama la atención sobre enfermedades transmitidas por el agua, se pretende el reconocimiento de los cuidados y los trabajos domésticos no remunerados a través de servicios públicos e infraestructuras necesarias, o se solicita atender las necesidades específicas de las mujeres y las niñas en los servicios de saneamiento e higiene. Pero icómo lograr un reparto más equitativo de tierras y facilitar el acceso de las mujeres en la agricultura? ¿qué servicios son necesarios para facilitar y conciliar el

Feminismo/s 32, diciembre 2018, pp. 23-47 
desempeño de cuidados y tareas no remuneradas en condiciones de igualdad? ¿a qué necesidades específicas de la mujer se refiere?

Previsiblemente, cada región debería alcanzar, desde su Agenda Urbana, los niveles de especificidad adecuados para afrontar los diferentes retos y oportunidades en función del tamaño, la escala y el contexto cultural o geográfico que deban abarcar. En este tema en concreto, la repercusión en las relaciones sociales al dotar de agua corriente y de electricidad a una aldea del interior de España y clausurar su lavadero, no serían las mismas que hacerlo en otros territorios donde acudir al lavadero representa uno de los pocos pretextos que las mujeres tienen para salir de sus casas y relacionarse con otras mujeres, aunque en ambos casos se estarían limitando posibilidades de uso para un espacio abierto y público. Perfectamente, el lavadero podría adaptarse a las actuales condiciones de vida, evitando la segregación, pero sin perder la memoria del lugar. De hecho, esto ya se produce de algún modo cuando, de manera espontánea, los lavaderos se convierten en espacios de encuentro o cuando en algunas poblaciones son los hombres quienes acuden a limpiar la paella.

Lo cierto es que analizar todas las agendas urbanas de otras naciones excede a nuestra voluntad, por lo que no podemos constatar si la limpieza de las ropas, como necesidad humana, cubierta exclusivamente gracias al trabajo de las mujeres, encuentra amparo, protección y alternativas. Nos centraremos, entonces, en la Agenda Urbana Española (AUE) teniendo en cuenta que, en cualquier caso, este tipo de documentos no tiene carácter normativo sino estratégico.

Lógicamente, en la AUE no encontramos consideraciones explícitas sobre la limpieza de la ropa, que podría considerarse un tema secundario derivado del conjunto de cuestiones que impiden la igualdad efectiva entre hombres y mujeres. Sin embargo, es curioso que uno de los nueve ítems que el indicador AROPE (At Risk Of Poverty or Social Exclusion) empleado para determinar el riesgo de pobreza o exclusión social en el diagnóstico de la AUE, sea el disponer de lavadora en el hogar ${ }^{4}$. Esto es relevante porque, a pesar de esa aparente

4. Los otros ocho serían: poder pagar el alojamiento y facturas corrientes; mantener la vivienda con temperatura adecuada en invierno; poder ir de vacaciones fuera de casa una semana o más al año; comer carne o pescado cada dos días al menos; poder afrontar gastos imprevistos; o tener teléfono, TV en color o coche.

Feminismo/s 32, diciembre 2018, pp. 23-47 
relación entre la dificultad para la limpieza de ropas y la carencia material extrema, y de que el Objetivo Estratégico 6 pretende la cohesión social y la equidad reduciendo el riesgo de pobreza y exclusión social en entornos urbanos desfavorecidos, pero también buscando la igualdad de oportunidades desde una perspectiva de género, edad y capacidad, no encontramos en el documento opciones para paliar las consecuencias directas de esa carencia. Tampoco se evidencian directrices capaces de incidir en la redistribución de las tareas en el hogar y apenas hay referencias al trabajo no remunerado. En definitiva, aunque la AUE plantea escenarios positivos para mejorar la estructura urbano-espacial de las ciudades ${ }^{5}$, no parece despejar el futuro incierto para algunas situaciones cotidianas en la vida de la ciudadanía que siguen teniendo un horizonte difuso. En nuestra opinión, los planes y programas de desarrollo de la AUE que pretendan un mayor equilibrio territorial para evitar el despoblamiento del medio rural o procuren, tanto en ámbitos rurales como urbanos, conservar y poner en valor el patrimonio cultural, deberían profundizar en estas cuestiones a partir de sus objetivos estratégicos y específicos.

La cuestión del patrimonio, entendida de un modo dinámico más relacionado con los valores que la sociedad le atribuye que con una idea estática de objetos y bienes a conservar, tiene mucho que ver con la memoria y, en el caso de los lavaderos, tendría que ver con la experiencia de las mujeres.

En un texto reciente María Ángeles Durán presenta la memoria urbana como un «palimpsesto en que todo se describe, se borra, se vuelve a escribir. La memoria de las ciudades la construimos por acumulación y filtrado de selecciones. No hay nada tan mentirosos y volátil como ella [...]. Los hombres muestran una extraordinaria debilidad por la piedra y el hierro, las huellas duraderas [...]. Pero las mujeres: ¿dónde dejan su memoria? La mayoría la depositan en afectos, en actividades cotidianas que apenas hechas se desvanecen como retazos de vida» (39-40). Y a continuación reproduce la anécdota de un pueblo del interior en el que ubicaron la estatua de una lavandera junto a un pilón donde, según dicen, nunca se lavó.

5. Entre otros aspectos, la AUE se preocupa de apoyar «la movilidad de cuidado» sin limitar las opciones vitales de las mujeres ni perjudicar el modo en que éstas llevan a cabo sus múltiples responsabilidades en la esfera pública y en la esfera privada.

Feminismo/s 32, diciembre 2018, pp. 23-47 
Evidentemente un hecho así nos parece preocupante e inadmisible, representa una falsedad comparable a la que, en algunas restauraciones de lavaderos supondría eliminar el agua de la pila, sustituir elementos tipológicos por meras imitaciones, o algo bastante habitual como poner una reja y cerrarlos con llave para, supuestamente, conservarlos en mejor estado. Defendemos, en cambio, un mayor rigor en la documentación y tratamiento de estos lugares que incorpore las reivindicaciones y recuerdos de las mujeres que los usaron -por humildes que fueran-y asuma una visión amplia y plural del patrimonio capaz de resignificar y plantear transformaciones respetuosas.

No se trata de una tarea fácil ni exenta de controversia, ya que el espacio del lavadero arroja luces y sombras a la hora de interpretar las vivencias y la memoria de las mujeres.

Para empezar, debemos admitir que, a pesar de su relevancia como espacios de relación entre mujeres, no dejaba de reflejar una segregación sexual del espacio que confería al casino y al café una condición eminentemente masculina mientras que los lavaderos comunitarios representaban un dominio íntegramente femenino. Es decir, que para los hombres el café era un espacio de ocio, enmarcado en una esfera propia, mientras que para las mujeres se trataba de un espacio de trabajo relacionado con actividades de cuidado propias de la esfera reproductiva (Casanovas 325).

Es más, el lavadero sirvió para perpetuar los roles de género con desigual incidencia en hombres y mujeres ya que para ellos suponía un espacio ajeno mientras que para ellas representaba un espacio propio, lo cual ha generado una memoria diferenciada: para los hombres desde un imaginario estereotipado y peyorativo construido sin el conocimiento real de los sucesos (Gallego) y para ellas cargado de experiencias de apropiación reales.

Topónimos asignados por hombres a emplazamientos cercanos a los lavaderos, como «la curva les tetes» ${ }^{6}$ en Coya, Asturias (Cueli 26), recrean esa visión desde fuera que contrasta con la sensación de pertenencia de las mujeres a esos espacios exclusivos para ellas. Jordi Sebastià relata una experiencia en Mozambique explicando que «las seguimos por el camino del Zambezi, admirados por el equilibrio con que llevan sobre la cabeza vasijas llenas de

6. «En Montecoya (Coya), al pie de la riega Caballar, había un llavaderu formáu por delles llàbanes descubiertes que dio llugar a un llamativu -sí, y sexista- topónimu: «la curva

Feminismo/s 32, diciembre 2018, pp. 23-47 
vajilla o ropa amontonada para lavar. Se acercan a la orilla, se sorprenden y ríen. Vemos que alguna se sumerge en el agua y aprovecha para lavarse. Desistimos de pedir permiso para fotografiar, sentimos que estamos perturbando un espacio íntimo y volvemos al poblado [...]. Graça nos explica: Ese lugar del río es sólo para las mujeres, nos lavamos y hacemos nuestras tareas allí. Vosotros no sois de aquí y no lo sabíais, no pasa nada, pero los hombres de aquí no se acercan, saben que no es su sitio» (43).

Esta misma idea de identificación se puede observar en algunas películas en las que aparecen personas lavando. En el largometraje El Lute: camina o revienta hay una escena de la prisión de hombres en la que varios reclusos se encuentran lavando sus ropas mientras mantienen conversaciones subidas de tono, desafiantes y de marcado contenido sexual, lo cual ilustra con claridad su percepción del lavadero como un lugar de confidencias escandalosas y/o conflictivo. Sin embargo, en el remake mejicano de Marcelino, pan y vino se ve a mujeres felices, cuidando de sus hijos e hijas además de compartir en armonía la tarea de lavar y tender junto al río; al igual que sucede en la escena de Camino a la Escuela en la que una niña lava su uniforme del colegio en compañía de otras mujeres (figura 4), con las que se establece una relación de afecto, o en Rastros de sándalo. El cine refleja, en general, que la imagen de las mujeres lavando se da en clave colectiva y de sororidad, mientras que ellos aparecen en soledad. Otros ejemplos muestran a un niño apartado lavando

les tetes». Y ye que dende un xiru que facía'l vieyu trazáu de la carretera N-634 los conductores de los vehículos que pasaben per ellí podíen ver de frente a las muyeres llavando 1 ropa, qu'al tar agachaes y nun terrén un poco empozáu enseñaben parte'l pechu al traviés del escote la camisa».
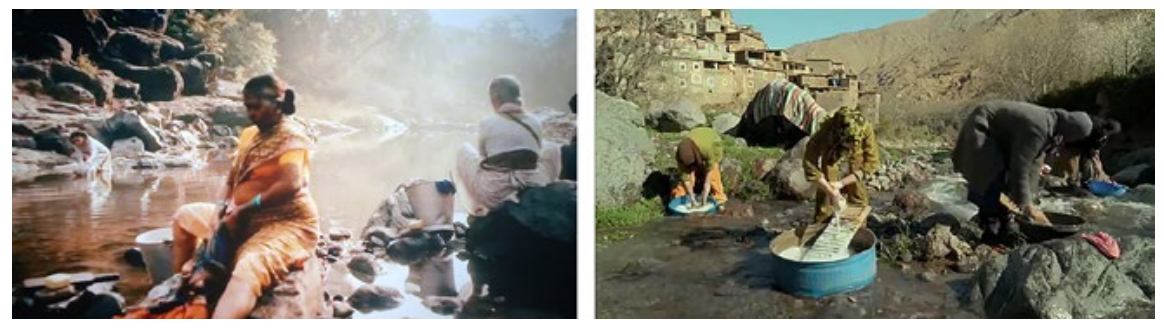

Figura 4. Fotograma de la película Rastros de sándalo de María Ripoll, fotograma de la película Camino a la escuela de Pascal Plisson.

Feminismo/s 32, diciembre 2018, pp. 23-47 
su uniforme en Camino a la escuela, a un hombre solo en el río y mujeres juntas al fondo en Los viajes del viento, escenas de amor entre mujeres en un lavadero en Un amor de verano, o reprimenda a una niña por estar en la zona masculina del río en Tanna.

Con todo lo expuesto, sobre esta necesidad de establecer un marco interpretativo, cabe un análisis transversal que rompe y expone una categorización del lavadero como un espacio que, aunque lo exijamos recuperado en su uso y la actividad de lavar, es también un lugar que puede leerse desde múltiples interpretaciones, a veces contradictorias. Cabría presentar alguna de ellas, de modo que permita proponer usos según referencias actuales sobre la cohesión social, la equidad, o la igualdad de género según expone la agenda urbana. Por ello, planteamos a su vez una definición del lavadero desde otro modo de ver que tiene en cuenta su recuperación según nuevas deducciones.

Si conceptuamos el periodo que se sitúa en los últimos veinticinco años del siglo XX, tras la proliferación de la lavadora como aparato doméstico ${ }^{7}$, la actividad de los lavaderos sucumbe progresivamente. No es motivo de este escrito estudiar por qué son abandonados muchos lavaderos, pero sí lo es investigar cómo influyeron en su momento, incluso hoy en día. La investigación trata de esclarecer por qué un espacio es construido exclusivamente para que las mujeres laven ropa y cómo, con el tiempo, prolifera como tipología arquitectónica al implantar las políticas higienistas en numerosos municipios entre finales del XIX y mediados del XX. Esto nos lleva a elaborar ciertas hipótesis relevantes para determinar las intencionalidades sobre un lugar conformado con ese «único» fin.

7. Aunque la difusión de la lavadora en Europa se produce después de la Segunda Guerra Mundial, su utilización en multitud de municipios en España no se lleva a cabo hasta que no llega la conducción del agua potable a las casas, que sucede casi en el último cuarto del siglo XX. Teniendo en cuenta que la conducción del agua suponía dejar un conducto que daba agua a un patio interior, la utilización de la lavadora no se llevará a cabo, en muchos casos, hasta ya entrados el último cuarto de siglo. Esto supondrá que muchos de los lavaderos de numerosos municipios de España se mantendrán en uso hasta finales del XX.

Feminismo/s 32, diciembre 2018, pp. 23-47 
No deja de ser curioso que muchos lavaderos sean públicos. En un momento en que los pueblos casi no disponían de dotaciones ni infraestructuras para el bien común -salvo una fuente, el mercado, o un matadero- se decidía la construcción del lavadero ${ }^{8}$ con el fin de mejorar las condiciones de mujeres lavando en ríos o arroyos mediante tablas de piedra. Y aunque las condiciones higienistas sean motivo para asegurar algunos logros de progreso en zonas rurales, no era tanto el espacio construido sino la conciencia de las mujeres quienes garantizaban los nuevos modelos. Al mejorar las condiciones de trabajo, las mujeres podrían sentirse consideradas. Anteriormente, sus condiciones de trabajo eran más duras y, si bien en algunos lavaderos la posición que adoptaba la mujer seguía colocándola arrodillada y no siempre se garantizaba una ergonomía cómoda, sí se producía en la mayoría de ellos. Con la construcción del lavadero, el agua se acerca a las manos y la posición de la mujer erguida mejorará las condiciones de la actividad de lavar ropa; donde la piedra dispuesta acorde al cuerpo posibilitará, al permanecer levantada, acompañar el ritual del lavado con conversaciones, confidencias, chismorreos y risas ${ }^{9}$. En este sentido debemos considerar que la construcción de los lavaderos supondrá no sólo la mejora de las condiciones en que se realizaba esa actividad por parte de las mujeres -ya que ningún hombre se dedicaba a lavarsino que además, tal como explica Beatriz Gallego, supondrá un cambio de mentalidad al permitir trasladar esa actividad a «un edificio pensado para ellas [...] dando un marco físico y público a un trabajo exclusivamente femenino y que, salvo en los casos en que era desarrollado por personas asalariadas que lavaban para otros, no trascendía más allá del ámbito doméstico. De hecho, podría decirse que se trata del único edificio [...] construido para las mujeres, lo cual le confiere una identidad propia» (Gallego Muñoz).

8. Es curioso que la construcción de los lavaderos fuera llevada a cabo y decidida por los hombres.

9. Obviamente, también será lugar en momentos de desesperación. Hoy, cuando se visita un lavadero, entre las pintadas hechas por algún grupo de jóvenes que acuden para disponer de un lugar en el que quedar con sus amistades, se pueden evocar los momentos en que las mujeres llenaban el lugar entre conversaciones con el sonido del agua de fondo. Estas conversaciones podrían reflejar muchas veces tristezas y desesperanza entre guerras y enfermedades que asolaban las poblaciones del XIX y principios del XX.

Feminismo/s 32, diciembre 2018, pp. 23-47 
No obstante, este acercamiento -el de disponer de un lugar donde se lavaba la ropa cerca de las casas del municipio- supondrá para la mujer una serie de nuevas condiciones que, como trasfondo, ponen en evidencia otras muchas cuestiones que hoy en día no pueden considerarse como mejora. Esto no quiere decir que no las disfrutaran. Al revés, mediante la exposición trataremos de enumerar de manera dispersa esas mejoras logradas tras su construcción, aunque también expondremos nuevas interpretaciones. Analizando otras condiciones organizativas, funcionales, o incluso sensitivas, podríamos ofrecer otra manera de entender e interpretar su influencia posterior en sus modos de vida.

Una de nuestras preocupaciones son las condiciones intrínsecas que puede conllevar el lavadero sobre finalidades ocultas para el control del trabajo de la mujer. Según expone Cristina Cantero en su libro sobre el agua en la vida cotidiana de Asturias «la necesidad de acudir a los ríos para lavar y coger agua suponía un riesgo para la moral que, sin duda, las autoridades tuvieron en cuenta a la hora de dotar de servicio de agua a pueblos y ciudades». Frente a esos lugares periféricos, sin vigilancia ni normas «las fuentes y lavaderos situados dentro de los pueblos eran espacios radicados en la «civilización», donde los comportamientos y las actitudes de sus usuarios estaban a la vista de todos y, por tanto, se procuraba no hacer nada que contraviniese las convenciones sociales y supusiese enfrentarse a la crítica de la comunidad» (59).

Desde unas condiciones referidas a la privacidad, aunque los significados sobre lo privado puedan ser distintos según qué momento, si tenemos en cuenta que estamos hablando de la segunda mitad del siglo XX y conceptuado a zonas rurales del estado español, el éxodo a la ciudad tras la guerra civil española va a ocasionar una mezcla de distintas y nuevas visiones sobre lo privado que van a influenciar nuestra percepción de hoy. La diferencia sustancial en el uso del tiempo propio nos remite al concepto de privacidad que, como desenmascara el libro El mito de la vida privada, tiene un doble sentido $y$, mientras para unos significa disponer de un tiempo propio, para otras se asimila a lo doméstico donde el tiempo se dispersa en atender y dar respuesta a las necesidades de otros (Murillo XXII). Estas situaciones van a poner en evidencia condiciones que han afectado y se han instaurado en los modos de vivir de la mujer, directa o indirectamente. El estudio plantea dudar sobre las

Feminismo/s 32, diciembre 2018, pp. 23-47 
apreciaciones centradas exclusivamente en las mejoras que los lavaderos han supuesto, introduciendo otra óptica en relación a la vida laboral.

La construcción de un lugar para lavar, el hecho de reunir a las mujeres en un espacio cercano al trazado urbano o incluso en el centro de la población, supone un control hacia la mujer al ser el lavadero un espacio abierto en el que deberá estar trabajando. Por sus características visuales, la mujer estará a expensas de la mirada, en donde es ella quien se presenta visible desde fuera. Estas condiciones carentes de privacidad ${ }^{10}$ van a predisponer a determinadas mujeres a una falsa independencia y a una fiscalización de su trabajo. Con la construcción del lavadero, la mujer va a disponer de un lugar cerca de casa, pero expuesto a las miradas de los hombres y de las otras mujeres del pueblo. Saldrá de casa y, en esos recorridos diarios, se darán encuentros fortuitos, se enterará de las noticias del día o intercambiará chismorreos (Perrot 77). Sin embargo, el lavadero supondrá una especie de regulación, para estar a expensas no solo de la posibilidad del control visual sino también del de la ocupación del tiempo de trabajo por el hecho de rendir cuentas y rentabilidad. Por un lado, esto supone -a diferencia de los hombres que se reúnen en un recinto cerrado y fuera del tiempo de trabajo- que el espacio que las mujeres tienen para reunirse queda vinculado a una actividad «laboral» además de encontrarse a la vista. En esa época la mujer está localizada entre la casa, el lavadero, el campo y la iglesia.

En el lavadero, el tiempo de la mujer en su cotidianeidad -permanentemente ocupado por el trabajo y expuesto a un control visual- tendrá una repercusión negativa para su desarrollo futuro teniendo en cuenta, además, que en muchos casos la labor no se considerará trabajo y no tendrá remuneración alguna. Esto podría explicar que, en una zona rural donde la mujer era la encargada de cualquier trabajo -actividades como arar la tierra, recolectar, mover el ganado, cargar los carros de trigo o incluso trillar las mieses, más veces de las pensadas eran faenas realizadas por mujeres sin tiempo para el descanso- no haya trascendido este reconocimiento hasta nuestros días.

La película del cineasta español Jacinto Esteva, Lejos de los árboles -como ensayo fílmico sigue «una interesante línea antropológica» (Delgado

10. Al no existir una concepción de la privacidad como la entendemos ahora, esta es planteada justamente por su ausencia.

Feminismo/s 32, diciembre 2018, pp. 23-47 

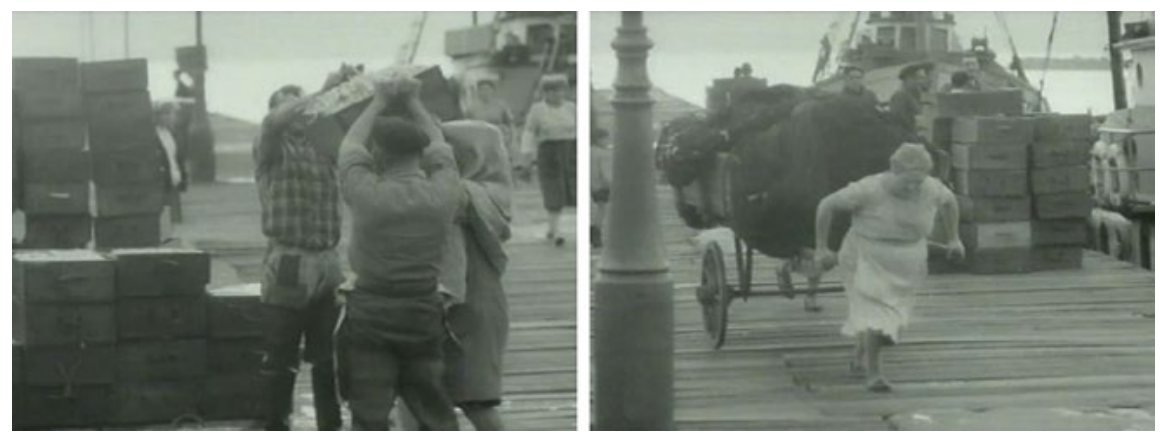

Figura 5. Dos fotogramas de la película Lejos de los árboles de Jacinto Esteva. Mujer ayudada por dos hombres para cargar una caja de pescado y mujer trasportando carro de redes.

225)- expone en uno de sus capítulos el trabajo femenino y el sometimiento de las mujeres en Galicia. Muestra numerosas labores realizadas por la mujer en un entorno rural. La película es desarrollada en un momento que coincide con el uso de numerosos lavaderos. Las imágenes, tomadas entre 1963 y 1971, presentan situaciones difíciles de ver según los largometrajes que se producían en el estado español durante la dictadura franquista ${ }^{11}$. En una de sus filmaciones, iniciada con una toma en un puerto gallego, numerosas mujeres hacen cola para cargar cajas llenas de pescado entre la mirada atónita de chicas que se ubican alrededor. Dos hombres levantan una caja repleta de pescado, cada uno por uno de sus lados y, tras un impulso, la elevan sobre la cabeza de una mujer y, posteriormente, una tras otra, trasladan el pescado desde su llegada a tierra hasta la lonja donde será vendido (figura 5). Las cajas de madera, transportadas a pie, son apoyadas sobre pañuelos que las cubren mientras las sujetan pasando sus brazos por encima. Alguna de ellas se atreve a soltarla en un alarde de equilibrio, mientras algunos chavales se dispersan alrededor mirando a la cámara ${ }^{12}$. Tras la escena, otra mujer carga un carro lleno de

11. Surcos de José Antonio Nieves Conde, o La ciudad no es para mí de Pedro Lazaga, son algunas de las películas del régimen que imponían diferencias sobre lo rural y urbano que Jacinto Esteva, justamente, liga para expresar que una conlleva la otra.

12. Más que por la curiosidad de ver el trabajo que hacían las mujeres, o lejos de criticar el inicio de muchas de las situaciones actuales de la mujer en el mundo laboral, las chavalas y los chavales que se agolpaban alrededor de la cámara estaban acostumbradas

Feminismo/s 32, diciembre 2018, pp. 23-47 
redes de pesca. En un acercamiento hacia el lugar de la filmación muestra el sobreesfuerzo de tirar con sus brazos el artilugio, que con sus ruedas de aros de hierro rebasa un suelo lleno de socavones tras coger impulso (figura 5).

Después de las filmaciones del puerto, un plano en movimiento desde la copa de los árboles hasta el suelo nos ubica en el campo. Protagonizado de nuevo por numerosas mujeres encargadas de segar el trigo, hacer fardos, arar la tierra, cavarla, afilar hoces, dirigir los bueyes, ubicar el arado, alinear los caballones, apilar los fardos o cargar un carro con montañas de trigo (figura 6), estas serán motivo de una mirada fílmica que nos sirve para documentarlo. La filmación acaba con el fin de la jornada laboral. A un carro acompañado

a ver algo que, aunque en ese momento no fuera con ellos, realmente tendrá su implicación generacional.
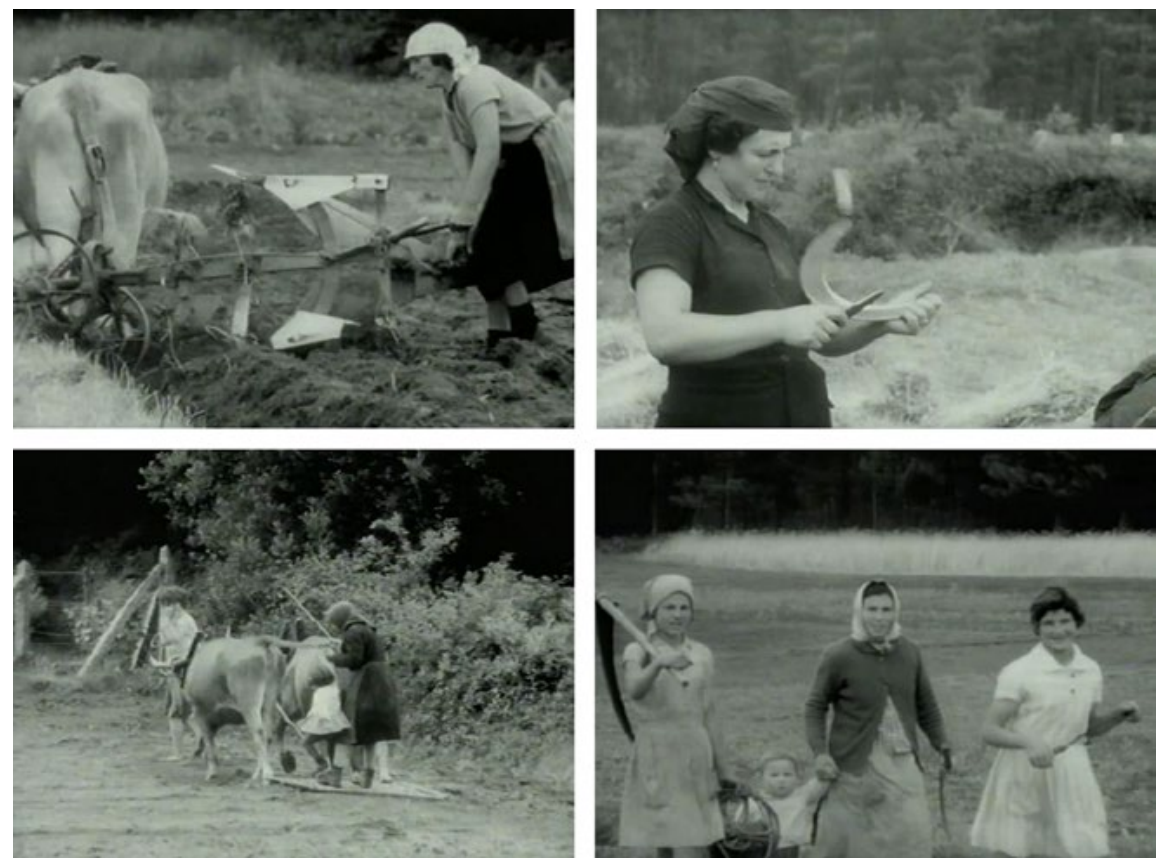

Figura 6. Cuatro fotogramas de la película Lejos de los árboles de Jacinto Esteva. Mujer arando con buey y mujer afilando hoz, mujer subiendo a su hija sobre tabla cargada por bueyes, mujeres después de la jornada en el campo.

Feminismo/s 32, diciembre 2018, pp. 23-47 
por ellas le sigue otra imagen de una mujer que coge a su hija del brazo para subirla repentinamente a una trillera tirada por dos bueyes (figura 6). En otra imagen tres mujeres miran a la cámara satisfechas por haber terminado su jornada. Sus manos, ocupadas con las hoces y la guadaña, así como sus miradas, nos definen la dureza de la jornada. Una de ellas lleva a su hijo de la mano, también mira a la cámara en su camino a casa (figura 6). Jacinto Esteva, «formado como urbanista y arquitecto, [...] quiso contribuir con Lejos de los árboles a desmentir el falso divorcio entre lo rural y lo urbano y a reflexionar de otro modo sobre la ciudad, mostrando cómo se agitaban en ella las mismas fuerzas de lo distinto y lo incalculable.» (Delgado 228)

De la misma manera que Jacinto Esteva, con Lejos de los árboles, nos acerca a la ciudad - «la película se abre y concluye en escenarios plenamente urbanos» (Delgado 226)-, un lavadero, en cualquier enclave rural, nos ubica también en la ciudad de una forma parecida a como lo hace el director de la Escuela de Barcelona. Lejos de los árboles nos muestra el lado oculto de la tradición, nos enseña el ámbito propio que sustenta las costumbres y que debe esconderse justamente por la violencia y crueldad que la película evidencia. Mientras que, en la película, la imagen del baile en una discoteca de la Costa Brava puede relacionarse con las imágenes de «la batalla del vino, por San Pedro, en Haro» (figura 7); la crueldad de matar un burro despeñado por un acantilado contrasta con el toreo en cualquier plaza de toros (figura 8). Estos vínculos entre el mundo rural y el mundo urbano, que son mostrados sin una pretensión por denunciar la violencia sino más bien para presentar estos
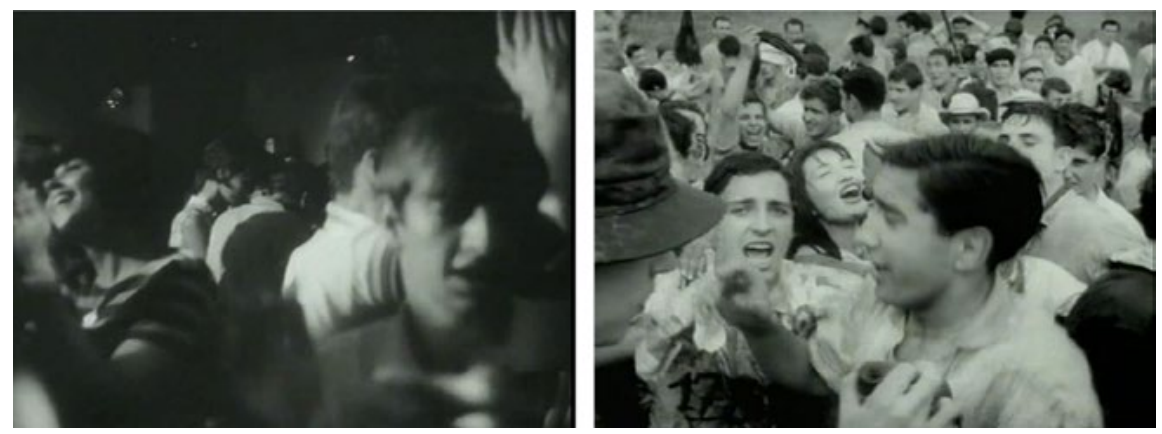

Figura 7. Dos fotogramas de la película Lejos de los árboles de Jacinto Esteva. Chicas y chicos bailando en una discoteca de Girona. Chicas y chicos bebiendo vino en Haro.

Feminismo/s 32, diciembre 2018, pp. 23-47 

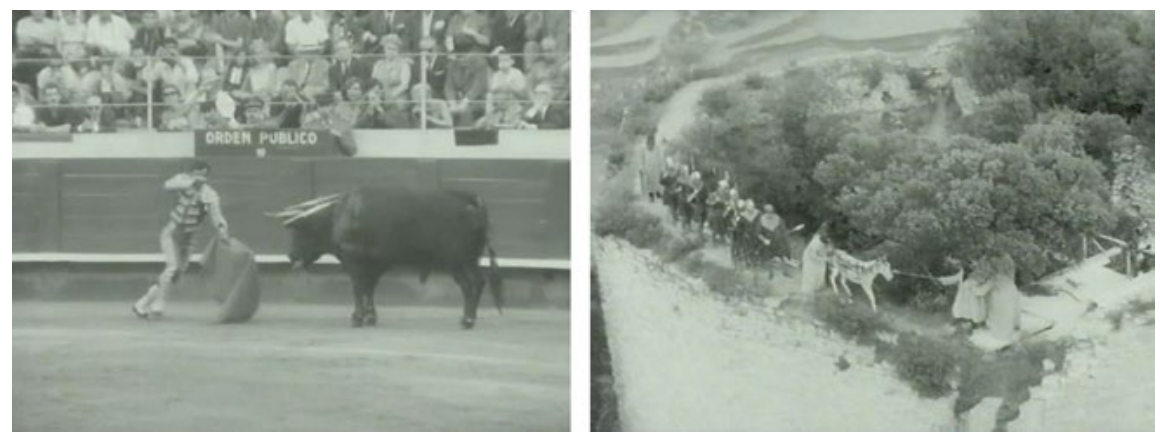

Figura 8. Dos fotogramas de la película Lejos de los árboles de Jacinto Esteva. Torero antes de dar muerte a un toro y un burro que representa el diablo antes de ser despeñado.

hechos, nos lleva justamente a la posibilidad de establecer ciertas proximidades allí donde han sido encubiertas. «Su asunto es en realidad lo alterno, lo otro, lo que, desmintiendo toda normalidad, hay razones para sospechar que la alimenta» (Delgado 227).

Un lavadero rural, con el sonido del agua constante en su paso, nos presenta un ámbito que llevado a la ciudad podría vincularse, no solo con lavaderos como los del Manzanares, sino también con la industria textil de muchas capitales, justamente por ser las mujeres quienes trabajaban en ellos por sueldos miserables.

En el interior de un lavadero se podrían evocar continuas quejas. Para que las clases superiores dispusieran de un ajuar en condiciones, pagaban a lavanderas precios irrisorios, sobretodo en las ciudades, donde un numeroso grupo de lavanderas a diario les lavaban las prendas. Son muchos los dichos sobre lavaderos: lugares en los que las mujeres se reunían, charlaban y reían ${ }^{13}$. Pero también allí se organizaban como mujeres, callaban intimidades, conocían sucesos, mostraban nuevas inquietudes en la crianza y las

13. Algunas palabras o expresiones en castellano resultan significativas por el carácter peyorativo que revierten en los lavaderos. Expresiones como «lavar los trapos sucios», «los trapos sucios se lavan en casa» o «haber ropa tendida» coinciden en vincular el lugar en que las mujeres acudían a lavar la ropa con otra actividad que sería intercambiar confidencias o hablar de personas que no estaban presentes.

Feminismo/s 32, diciembre 2018, pp. 23-47 
más progresistas enseñaban panfletos para luchar sobre unas mejores condiciones ${ }^{14}$. Cuando alguna de las hijas llegaba de la ciudad y acompañaba a su madre a lavar, contaba cómo se constituían en las fábricas, a las que había asistido como costurera desde la tradición estructurada para la pobreza que evitaba su alfabetización ${ }^{15}$. Para disponer de mano de obra barata se escogía a mujeres que no habían pasado la pubertad, para, sin apenas condiciones laborales, ser explotadas en las industrias. Se les exigía, en largas jornadas de trabajo entre 10 y 12 horas, una labor continua en malas condiciones y unos salarios bajísimos ${ }^{16}$. Si hay algo que está ligado al capitalismo, además de las malas condiciones laborales, son las mujeres y la infancia en la industria.

Los lavaderos, como tipología, surgen a la vez que la industria. Se establecen en un mismo periodo. Si tenemos en cuenta el papel de las lavanderas en las grandes ciudades ${ }^{17}$, los lavaderos, quizá, tengan más que ver, de lo que en un principio se pudiera pensar, con la industria textil y la explotación laboral de las mujeres. En los lavaderos de las grandes ciudades era explotado el trabajo de la mujer. Al fin y al cabo, se podría decir que son el lugar donde la mujer que viene del pueblo encontrará un trabajo seguro, por su dominio en el lavado de ropa, y por imponerle estar continuamente vigilada. Estas

14. En la película Concepción Arenal, la visitadora de cárceles, de Laura Maña, la educación de las mujeres en las cárceles se realiza en el lavadero. En la película Sufragistas, es significativo que el movimiento obrero femenino surgiera precisamente en las lavanderías.

15. «No termina aquí, aún, el relato de los injustos atropellos de que se os hace víctimas. No, señoras mías, hay más. En numerosos talleres hemos visto, inclinadas angustiosamente sobre la tela en gestación, criaturas de 10 y menos años, a las cuales se les da un semanal de 2 pesetas o de una peseta con cincuenta céntimos, obligándolas el sábado a hacer lo que nosotras las mujeres llamamos vulgarmente fer dissabte» (Picornell 59-60).

16. «Las compañeras del ramo de sastrería, como todos los trabajadores en general, son vilmente explotadas y hasta humilladas. Las obreras de Can Figuerola no son un caso excepcional. Dichas obreras, después de trabajar 10 a 12 horas para sacar un mísero jornal, llega el día de pago y la mayoría no cobra, y a las que cobran sólo les pagan la mitad» (Picornell 93).

17. «Este 'campo de batalla' se anima a medida que llegan las lavanderas. Éstas pertenecen a tres categorías: las lavanderas profesionales que limpian la ropa de las burguesas, las amas de casa que lavan la ropa de su casa, y una categoría intermedia, las mujeres que lavan piezas sueltas, es decir, las que limpian a la vez su ropa y al mismo tiempo limpian alguna prenda de una tendera o de una vecina, para ganarse así un pequeño sueldo suplementario» (Perrot 80).

Feminismo/s 32, diciembre 2018, pp. 23-47 
condiciones servirán para una mayor explotación. De la misma manera que cientos de mujeres son reclutadas para trabajos en los lavaderos de las grandes ciudades, la industria textil es también el lugar para reclutarlas. Tienen un vínculo, por tratarse de un lugar de control, de vincularse a los tejidos, y por ser espacios protagonizados, en ambos casos, por mujeres.

\section{4}

Después de todo lo escrito, reivindicamos la conservación de los lavaderos. Evidentemente reclamamos el mantenimiento de los que todavía se mantienen en uso y proponemos la rehabilitación o acondicionamiento de otros existentes como un medio para recuperar la memoria de lo que han representado en nuestras poblaciones. Necesariamente esta conservación debería permitir una interpretación compleja de todas las experiencias acumuladas, aceptando una múltiple realidad dependiendo del enfoque de la mirada que se pretenda de ellos. Por una parte, consideramos que la conservación material de los lavaderos no debería desligarse de los cursos y la presencia del agua; ni tampoco se debería tergiversar la relación funcional o visual que los lavaderos mantenían con su entorno. Pero, además, de nada serviría tampoco conservar un objeto inanimado y carente del aliento humano que contuvo, ni musealizarlo ocultando sus diversas realidades.

No creemos necesario preservar todos los lavaderos, pero quizás sí aquellos más significativos o singulares, haciendo un esfuerzo especial por rescatar la memoria de las mujeres humildes y dar voz a sus padecimientos y reivindicaciones. Para esto, se debería documentar más y mejor sus experiencias en ellos.

Entendemos necesaria una lógica adaptación y transformación de estos espacios a nuestras actuales condiciones de vida permitiendo el disfrute colectivo de este equipamiento en clave de igualdad.

\section{REFERENCIAS BIBLIOGRÁFICAS}

Cantero Fernández, Cristina. El agua en la vida cotidiana. Fuentes, lavaderos y abrevaderos de Asturias. Gijón: Fundación Municipal de Cultura, Educación y Universidad Popular del Ayuntamiento de Gijón/Xixón, 2015.

Feminismo/s 32, diciembre 2018, pp. 23-47 
Casanovas, Roser. «La gestión de la vida cotidiana en las colonias textiles catalanas. Una aproximación de género». Estudios urbanos, género y feminismo. Coord. Blanca Gutiérrez Valdivia y Adriana Ciocoletto. Barcelona: Col-lectiu Punt 6, 2012. 301-328. <https://issuu.com/punt6/docs/ publicaciondefinitivaestudiosurbano>

Cueli Canto, Daniel. Los Llavaderos del Conceyu de Piloña. Santander: Fundación Belenos, 2015.

Delgado, Manuel. «El arte de danzar sobre el abismo». Memoria, imagen y fascinación. Memoria sobre el documental en España. Ed. Josep Maria Català. Madrid: Ocho y Medio, 2001. 221-230.

Durán Heras, María Ángeles. «La ciudad compartida: urbanismo y movimientos sociales». Género y política urbana. Arquitectura y urbanismos desde la perspectiva de género. Ed. Begoña Serrano Lanzarote, Carolina Mateo Cecilia y Alberto Rubio Garrido. Valencia: Instituto Valenciano de la Edificación, 2017. 33-57.

Gallego Muñoz, Beatriz. «Una aproximación a la sociabilidad femenina y a la creación de la conciencia de género: los lavaderos en el mundo rural alavés». Euskonews \& Media 578 (2011). <http://www.euskonews.eus/0578zbk/ gaia57802es.html>

Ministerio de Fomento. Versión 1.0 de la Agenda Urbana Española (AUE). 20 marzo 2018. <https://www.fomento.gob.es/arquitectura-vivienda-y-suelo/ urbanismo-y-politica-de-suelo/urbanismo-y-sostenibilidad-urbana/ agenda-urbana-espanola>

Moya Muñoz, Fernando. «Aprovechamiento tradicional del agua en Fuenterrobles». Oleana 21 (2006): 47-58.

Murillo, Soledad. El mito de la vida privada. De la entrega al tiempo propio. Madrid: Siglo XXI de editores, 1996.

Naciones Unidas. Agenda 2030. Resolución aprobada por la Asamblea General el 25 de septiembre de 2015. 20 marzo 2018. <http://www.un.org/es/comun/ docs/?symbol=A/RES/70/1>

Naciones Unidas. Nueva Agenda Urbana, 2017. 20 marzo 2018. <http://habitat3. org/wp-content/uploads/NUA-Spanish.pdf>

Perrot, Michele. «El ama de casa en el espacio parisino durante el siglo XIX». Historia Urbana 1 (1992): 71-82.

Picornell, Aurora. «Para las modistillas palmesanas». Aurora Picornell. Escrits 1930-1936. Ed. Josep Quetglas. Pins del Vallés: Associació d'idees, 2012. 
Sebastià, Jordi. La dignitat i l'aixada. Experiències de la lluita quotidiana de les dones africanes. Valencia: Asociación Fontilles, 2010.

Wigley, Marc. «Sense títol: Lallotjament del gènere». Sexualitat i espai. El disseny de la intimitat. Ed. Beatriz Colomina. Barcelona: Edicions UPC, 1997. 209-242.

\section{FILMOGRAFÍA}

Aranda, Vicente. El Lute: camina o revienta. España: MGC, 1987.

Bentley, Dean y Martin Butler. Tanna. Australia: Contact Films / Screen Australia, 2015.

Corsini, Catherine. Un amor de verano. Francia: Chaz Productions / France 3 Cinéma / Artémis Productions / Canal+ / Orange Cinéma Séries / France Télévisions / Jouror Productions / Indéfilms 3 / Soficinéma 11 / Cinémage 9 / Région Limousin / Centre National de la Cinématographie (CNC), 2015.

Esteva, Jacinto. Lejos de los árboles. España: Filmscontacto, 1972.

Guerra, Ciro. Los viajes del viento. Colombia: Coproducción Colombia-ArgentinaAlemania-Países Bajos (Holanda); Cine Ojo / Ciudad Lunar Producciones / Ibermedia / Universidad Nacional de Colombia / ZDF/Arte / Razor Film Produktion GmbH / Volya Films, 2009.

Gutiérrez Arias, José Luis. Marcelino, pan y vino. México: LOB Films, 2010.

Mañá, Laura. Concepción Arenal, la visitadora de cárceles. España: Distinto Films / Zenit TV / Televisió de Catalunya (TV3) / Televisión de Galicia / Canal Sur Televisión / TVE, 2012.

Plisson, Pascal. Camino a la escuela. Francia: Winds / Ymagis / Wild Bunch, 2013. Ripoll, María. Rastros de sándalo. España: Pontas Films, 2014.

Feminismo/s 32, diciembre 2018, pp. 23-47 